\title{
PW02-042 - Induction of MDSC in Muckle-Wells syndrome
}

\author{
N Rieber ${ }^{*}$, A Brand, D Neri, T Hall, I Schäfer, S Hansmann, J Kümmerle-Deschner, D Hartl \\ From 7th Congress of International Society of Systemic Auto-Inflammatory Diseases (ISSAID) \\ Lausanne, Switerland. 22-26 May 2013
}

\section{Introduction}

Muckle-Wells syndrome (MWS) is caused by mutations in the NLRP3-gene encoding cryopyrin, leading to overproduction of IL-1 $\beta$ and other NLRP3 inflammasome products. Myeloid-derived suppressor cells (MDSCs) represent a novel innate immune cell subset, are generated in tumor, infective, and proinflammatory microenvironments and are capable of suppressing $\mathrm{T}$ cell responses. Consequently, MDSCs are considered a key intermediary in balancing innate and adaptive immune responses, particularly under chronic disease conditions.

\section{Objectives}

We hypothesized that NLRP3 inflammasome-dependent factors induce the generation of MDSCs in MWS.

\section{Methods}

We studied granulocytic MDSC numbers in 25 MWS patients under anti-IL-1 therapy with canakinumab and 20 healthy controls. After Ficoll density gradient sedimentation, granulocytic MDSCs were characterized as CD33 ${ }^{\text {high }}$ CD $66 b^{\text {high }} I L-4 R{ }^{\text {inter }}{ }^{2}$ LA-DR ${ }^{\text {low }}$ neutrophilic cells in the PBMC fraction, according to previously established human MDSC analysis methods. The functionality of MACS-isolated MDSCs was assessed using polyclonal $\mathrm{T}$ cell proliferation and cytokine / chemokine secretion tests. Physician's global assessment of disease activity, CRP, ESR, and T helper cell subsets were determined at the same time points and correlated with MDSC levels. Serum samples of 22 MWS patients and 5 healthy controls were examined by multiplex technique for possible MDSC inducing factors.

\section{Results}

MWS patients under anti-IL-1 therapy displayed significantly elevated MDSC numbers (mean $1.65 \pm 0.33 \%$; range $0.16-5.17 \%$ ) compared to healthy controls (mean $0.45 \pm 0.05 \%$; range $0.12-1.04 \% ; p=0.0025$ ), although clinical MWS-disease activity was generally low at time of examination. MDSCs were functionally competent, as they suppressed polyclonal T cell proliferation, Th1, Th2, and Th17 responses. MDSCs correlated directly with Treg/Th17 and Treg/Th1 ratios indicating an influence on T helper cell subsets. Multiplex assays revealed the established MDSC-inducing growth factors GM-CSF and VEGF elevated in MWS sera even under anti-IL-1 therapy with canakinumab.

\section{Conclusion}

MWS patients under anti-IL-1 therapy display significantly elevated numbers of granulocytic MDSCs. Increased MDSCs in MWS might represent a novel autologous antiinflammatory mechanism in autoinflammatory conditions and may serve as a future therapeutic target.

\section{Competing interests}

N. Rieber Grant / Research Support from: I obtained research grant from Novartis GmbH in 2012, Paid Instructor at: I held a paid talk for Novartis GmbH in 2012, A. Brand: None declared, D. Neri: None declared, T. Hall: None declared, I. Schäfer: None declared, S. Hansmann: None declared, J. Kümmerle-Deschner Grant / Research Support from: Obtained research grants from Novartis GmbH, D. Hartl Grant / Research Support from: Obtained research grants from Novartis $\mathrm{GmbH}$

Published: 8 November 2013

doi:10.1186/1546-0096-11-S1-A183

Cite this article as: Rieber et al:: PW02-042 - Induction of MDSC in Muckle-Wells syndrome. Pediatric Rheumatology 2013 11(Suppl 1):A183. 